\title{
Anti-phosphatidylcholine antibodies in patients with brucellosis
}

\author{
M. A. CASAO, J. LEIVA*, R. DIAZ* and C. GAMAZO \\ Departamento de Microbiologia, Universidad de Navarra and * Departamento de Microbiologia, \\ Clinica Universitaria de Navarra, 31080 Pamplona, Spain
}

\begin{abstract}
An indirect ELISA was adapted to measure individual classes of anti-phosphatidylcholine (PC) antibodies in patients with brucellosis; a comparison was made with patients with other infectious diseases and healthy human controls. Immunoconjugates of $\alpha, \gamma$ or $\mu$ chain specificity were used. The results were compared with those of conventional tests for brucella antibodies, Rose Bengal, microagglutination (MAT) and Coombs tests, as well as with VDRL. The results indicated that although all sera from patients with brucellosis were VDRL negative, $97 \%$ of them (30 of 31) had higher levels of IgA or IgG anti-PC antibodies than the healthy control group. The IgM anti-PC antibodies isotype was not discriminatory between both groups. Seven sera $(19 \%)$ from patients with other infections had values of IgG anti-PC higher than those of the healthy group; three of them were VDRL positive. The mean ELISA values of IgG and IgA anti-PC (serum diluted 1 in 1600 ) in the brucellosis and healthy groups were: IgG, 0.80 SEM 0.17 versus 0.23 SEM 0.10 ; and IgA, 0.86 SEM 0.26 versus 0.35 SEM 0.15 . The sensitivity and specificity for the ELISA-PC were: IgG, $96.8 \%$ and $96.5 \%$, respectively; IgA, $90.3 \%$ and $89.7 \%$, respectively. Only one of 14 individuals clinically cured from brucellosis had significant IgG anti-PC antibodies. In contrast, all of these patients gave positive values in the conventional test for brucellosis. No correlation was found between the serum levels of IgA, IgG anti-PC by ELISA-PC and the results of the MAT or Coombs tests.
\end{abstract}

\section{Introduction}

Human brucellosis is caused by gram-negative bacteria of the genus Brucella, mainly, B. melitensis, B. abortus and $B$. suis. In acute brucellosis, the patient usually presents with bacteraemia. Isolation of the bacteria from the patient is the only conclusive evidence of brucella infection. However, the bacteraemia is usually of low intensity, and the majority of positive blood cultures are obtained between the seventh and 21 st days of incubation [1,2]. Therefore, brucellosis is usually diagnosed by serological tests. Those tests assaying specific antibodies to brucella LPS, i.e., Rose Bengal test and Coombs test, are of great importance in the initial diagnosis of the disease [1], although it is well known that such antibodies remain high even after recovery from the disease [3] and after treatment [4]. As a result, their role in evaluating disease outcome in patients is often difficult to establish. Therefore, it is reasonable to assume that the determination of the

Received 26 March 1997; revised version received 9 April 1997; accepted 22 May 1997.

Corresponding author: Dr C. Gamazo. humoral response against LPS-free brucella antigens could help to circumvent these problems.

Phosphatidylcholine (PC) is an unusual phospholipid in bacterial membranes [5], but is present in the outer membrane of Brucella spp. [6], and is probably exposed on the outer surface [7]. On the other hand, PC-liposomes are agglutinated and even lysed in the presence of serum from mice experimentally infected with B. melitensis (unpublished data). These results suggest the presence of anti-PC antibodies after brucella infection. Accordingly, in this study serum levels of anti-PC antibodies of the IgG, IgM and IgA classes were measured by ELISA in patients with brucellosis, and in healthy human controls. Serum specimens from patients with other infectious diseases, and individuals clinically cured of brucellosis were also included.

\section{Materials and methods}

\section{Subjects and sera}

The study investigated 105 serum specimens from separate individuals. Of the total, 31 patients (group 1) 
had clinical signs and symptoms of brucellosis and were microbiologically or serologically confirmed, or both. The rest of the sera were: group 2, 36 patients with other infectious diseases (summarised in Table 1); group 3, 29 healthy adults who had no history of brucellosis or contact with suspected infected animals; group 4, 14 individuals who had had brucellosis in the past and, although clinically cured, were serologically positive in conventional tests for brucella antibodies (Table 2). All sera were stored in small, divided samples at $-20^{\circ} \mathrm{C}$ until tested.

Table 1. Comparative serological results (MAT, VDRL and ELISA-PC) obtained in patients clinically diagnosed with infections other than brucellosis

\begin{tabular}{lccccc}
\hline & & & \multicolumn{2}{c}{ ELISA-PC $^{\dagger}$} \\
\cline { 4 - 6 } Infective organism & MAT $^{*}$ & VDRL & IgG & IgA \\
\hline Citrobacter freundii $(2)^{\ddagger}$ & - & - & - & - \\
Escherichia coli $(9)$ & - & - & - & - \\
Klebsiella oxytoca $(2)$ & - & - & - & - \\
Staphylococcus aureus $(5)$ & - & - & - & $+(1)^{\S}$ \\
Salmonella spp. (3) & - & - & - & - \\
Pseudomonas aeruginosa & - & - & - & + \\
Streptococcus mitis & - & - & - & - \\
Bacteroides distasonis & - & - & - & - \\
Bacteroides fragilis & - & - & - & + \\
Neisseria meningitidis & - & - & - & - \\
Enterococcus faecium & - & - & - & + \\
Candida albicans & - & - & - & + \\
Treponema pallidum (2) & - & + & + & + \\
HIV (2) & - & $+(1)$ & + & + \\
HBV (2) & - & - & $+(1)$ & $+(1)$ \\
Streptococcus pneumoniae & - & - & - & - \\
Leishmania donovani & - & - & - & + \\
\hline
\end{tabular}

${ }^{*}$ Titres of $<40$ are considered negative.

${ }^{\dagger} \mathrm{OD}$ values $\geqslant 0.55$ are considered positive.

${ }^{\ddagger}$ Number of patients infected with each micro-organism tested.

Number of positive samples out of the total.

Table 2. Comparative serological results (Rose Bengal, agglutination and ELISA-PC) obtained in patients clinically cured

\begin{tabular}{lccccc}
\hline & & & \multicolumn{2}{c}{ ELISA-PC $^{\dagger}$} \\
\cline { 4 - 5 } Patient no. & $\begin{array}{c}\text { Rose Bengal } \\
\text { test }\end{array}$ & $\begin{array}{c}\text { Agglutination* } \\
\text { titre }\end{array}$ & IgG & IgA \\
\hline 1 & + & 160 & - & - \\
2 & + & 160 & - & - \\
2 & + & 160 & + & + \\
3 & + & 160 & - & + \\
4 & + & 80 & - & - \\
6 & + & 160 & - & - \\
7 & + & 80 & - & - \\
8 & + & 160 & - & - \\
8 & + & 160 & - & - \\
10 & + & 80 & - & + \\
11 & + & 320 & - & - \\
12 & + & 160 & - & + \\
12 & + & 80 & - & - \\
14 & + & 160 & - & + \\
\hline
\end{tabular}

${ }^{*}$ Titres $\geqslant 40$ are considered positive.

${ }^{\dagger} \mathrm{OD}$ values $\geqslant 0.55$ are considered positive.

\section{ELISA}

The ELISA was performed essentially as described previously [8]. The following conditions were determined in preliminary experiments: $5 \mathrm{mg}$ of PC (L- $\alpha-$ phosphatidylcholine from fresh frozen egg yolk; Sigma) dissolved in PBS (10 mM phosphate-buffered saline, $\mathrm{pH} 7.2$ ) to give $50 \mu \mathrm{g} / \mathrm{ml}$ were applied to ELISA microplates (Maxisorp, Nunc, Roskilde, Denmark) at $37^{\circ} \mathrm{C}$ for $24 \mathrm{~h}$. The solution was then tipped off and the microplates were washed four times with PBST (PBS plus Tween-20 0.05\%). Serum samples were first diluted from 1 in 100 to 1 in 12800 in a separate test tube in PBST before being added to the ELISA plates. The plates were incubated at $37^{\circ} \mathrm{C}$ for $4 \mathrm{~h}$. Then they were washed four times as described previously. Three different anti-human Ig isotypespecific peroxidase conjugates were used: rabbit anti $\alpha$ chain (Pierce Chemical, Co., USA), $\gamma$ chain (Nordic Labs, Tilburg, the Netherlands), $\mu$ chain (Nordic), diluted at 1 in 1000,1 in 1000 and 1 in 500, respectively, in PBST. After $30 \mathrm{~min}$ at $37^{\circ} \mathrm{C}$, plates were washed and developed by incubation for $20 \mathrm{~min}$ at room temperature with 2,2'-azino-bis-3-ethylbenzothiazoline-6-sulphonic acid diammonium salt $0.01 \%$ (Sig$\mathrm{ma})$ in $0.1 \mathrm{M}$ citrate buffer $(\mathrm{pH} 4.0)$ containing hydrogen peroxide $0.01 \%$. The colorimetric values were determined by OD at $405 \mathrm{~nm}$. Tests of control negative and positive pool sera for brucellosis (see above) were repeated in all plates, and the results were expressed as the $\mathrm{OD}_{405}$ at the dilution giving the best discrimination between the negative and positive control sera.

\section{Microagglutination test (MAT) and Coombs test}

The MAT was done as described previously [9]. Briefly, two-fold dilutions of serum were made from 1 in 10 to 1 in 1280 with saline $(\mathrm{NaCl} 0.85 \%$ in distilled water) as the diluent $(50 \mu \mathrm{l} /$ well $)$ in U-shaped microtitration plates. These dilutions were doubled by adding $50 \mu \mathrm{l}$ of standardised $B$. abortus B19 inactivated cell suspension. The plates were vibrated briefly, and incubated at $37^{\circ} \mathrm{C}$ until the next day, and agglutination was determined. After reading the MAT titres, the antihuman immunoglobulin test (Coombs test) was set up. The plates were washed three times with saline, each washing consisting of centrifugation for $15 \mathrm{~min}$ at $350 \mathrm{~g}$. This was followed by a shaken inversion of the plates to eliminate the supernate, and finally, $100 \mu \mathrm{l}$ of the Coombs antigen (anti-IgG $\mathrm{H}$ chain; Dako $\mathrm{A} / \mathrm{S}$, Denmark) diluted in saline were added. After incubation at $37^{\circ} \mathrm{C}$ the results were read the following day.

\section{Rose Bengal test}

The Rose Bengal (RB) agglutination test was performed according to the method described by Morgan et al. [10]. The RB antigen was provided courtesy of F. Garrido (Laboratorio Sanidad-Producción Animal, 
Granada, Spain). Equal volumes $(20 \mu \mathrm{l})$ of serum and antigen were mixed on a white tile and the test was read after $4 \mathrm{~min}$. The appearance of agglutination indicated that the test was positive. A negative result was shown by a uniform homogeneous distribution of antigen.

\section{VDRL test}

Bacto VDRL antigen (Difco) was used for the VDRL slide qualitative test procedure as described previously [11].

\section{Data analysis}

The percentage specificity and sensitivity, and predictive values (the probability of a true diagnosis whether positive or negative) of the tests were calculated with Episcope 1.0 software (Agriculture University, Wageningen, the Netherlands) with a $95 \%$ confidence level. The proportion of observed test agreement was also calculated.

The data (OD values of the IgG and IgA ELISA-PC for the groups 1,2 and 3, and the MAT and Coombs titres) were analysed by means of the Statistical Package for the Social Sciences (SPSS), Chicago, USA. In comparisons of mean values, Student's $t$ test was used for normal data distribution and the MannWhitney $U$ test or Wilcoxon's test for abnormal distributions. Pearson's correlation test was used for simple correlation between the anti-Brucella immunoglobulin detected by ELISA (IgG, IgA) and the results of classical tests (MAT and Coombs). Differences with a $p$ value of $<0.05$ were considered significant.

\section{Results}

All serum specimens were diluted from 1 in 100 to 1 in 12800 , and the greatest difference between the OD of the positive and negative pool sera was 1 in 1600 for both IgG and $\operatorname{IgA}$ isotypes. Fig. 1 is a plot showing the evolution of the difference between a positive and a negative serum pool with respect to serum dilution. The IgM anti-PC antibodies isotype was not discrimi-

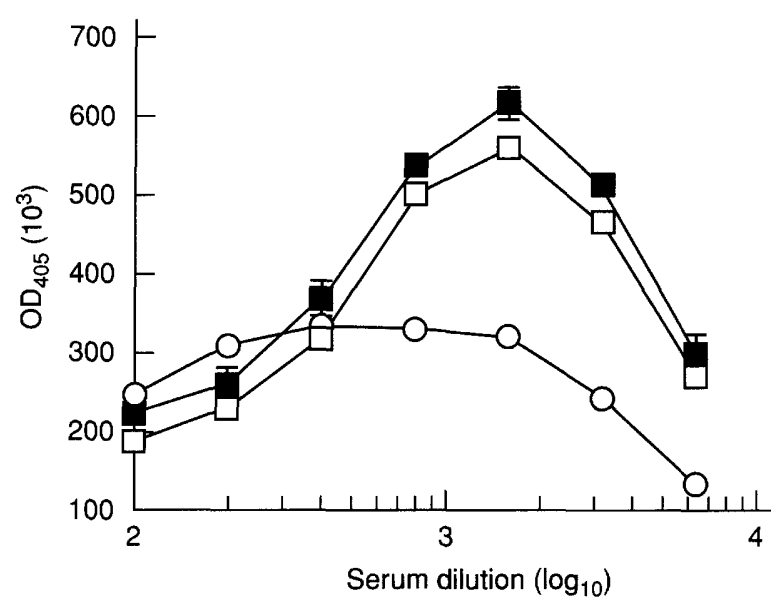

Fig. 1. Differences between the OD values of the positive (brucellosis) and negative (healthy controls) pool sera plotted against the corresponding dilution for antiphosphatidylcholine antibodies of IgA ( $\square), \operatorname{IgG}(\square)$ and $\operatorname{IgM}(O)$ isotypes. The mean and standard deviation of five independent experiments is shown.

natory between the two groups, consequently, this isotype was not assayed in the individual sera.

The results indicated that a significant anti-PC response can be detected in human brucellosis. The data in Table 3 show that although all sera from the patients with brucellosis were VDRL-negative, 90$97 \%$ of them gave positive values of $\operatorname{IgA}$ or $\operatorname{IgG}$ anti$\mathrm{PC}$ respectively. In contrast, only $3-10 \%$ of the sera from the healthy control group gave a positive anti-PC value. The mean values of $\operatorname{IgG}$ and $\operatorname{IgA}$ anti-PC (serum diluted 1 in 1600) in the brucellosis and healthy groups were as follows: for $\mathrm{IgG}, 0.80 \mathrm{SD} 0.17$ versus $0.23 \mathrm{SD} 0.10$; and for $\mathrm{IgA}, 0.86 \mathrm{SD} 0.26$ versus 0.35 SD 0.15 . A statistically significant difference was observed between the mean values of both $\operatorname{IgG}$ and $\operatorname{IgA}$ for brucellosis and healthy control groups $(p<0.05)$.

The OD values of sera from both populations were represented in frequency histograms (Fig. 2). The overlapping of the histograms from the positive (brucellosis) and negative (healthy control) groups for a given $O D$ value indicates the sensitivity and

Table 3. Comparative serological results obtained in patients clinically diagnosed as brucellosis cases, patients with other infections and healthy controls

\begin{tabular}{|c|c|c|c|c|c|c|}
\hline \multirow{3}{*}{$\begin{array}{l}\text { Group } \\
\text { (number tested) }\end{array}$} & \multicolumn{6}{|c|}{ Percentage of patients with positive results in } \\
\hline & \multirow[t]{2}{*}{$\mathrm{RB}$} & \multirow[t]{2}{*}{ MAT $^{*}$} & \multirow[t]{2}{*}{ Coombs $^{\dagger}$} & \multirow[t]{2}{*}{ VDRL } & \multicolumn{2}{|c|}{ ELISA-PC ${ }^{\ddagger}$} \\
\hline & & & & & IgG & $\operatorname{IgA}$ \\
\hline Healthy controls (29) & 0 & 0 & 0 & 0 & 3.4 & 10.3 \\
\hline Brucellosis patients (31) & 100 & 90.3 & 71.0 & 0 & 96.8 & 90.3 \\
\hline Other infections (35) & 0 & 0 & 0 & 8.3 & 14.3 & 31.4 \\
\hline
\end{tabular}




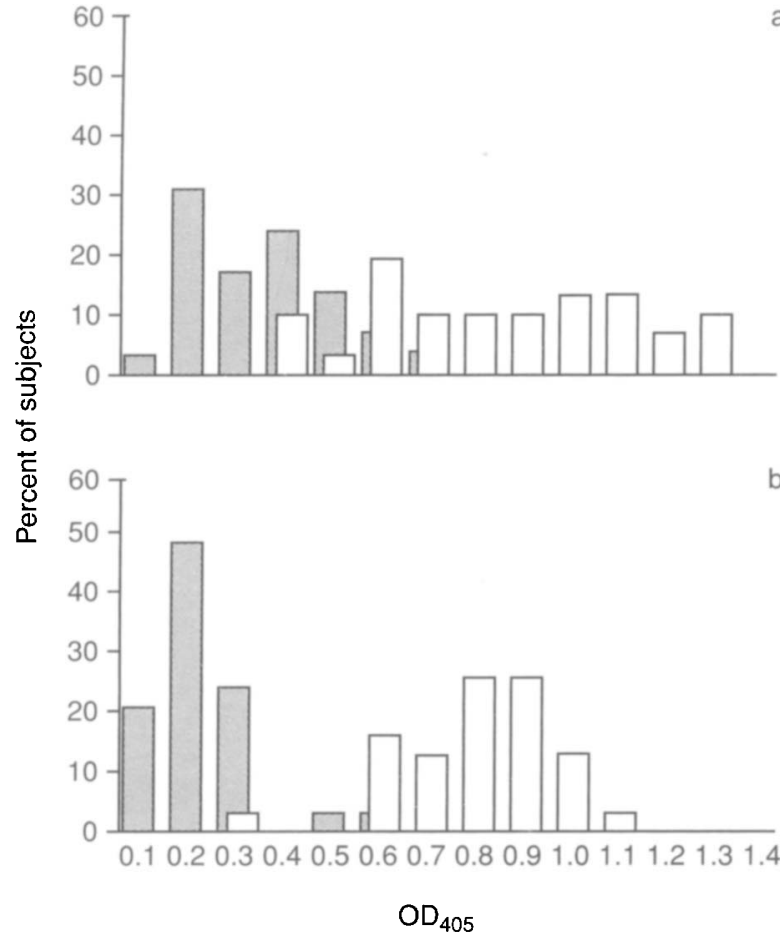

Fig. 2. Distribution of the absorbance values of the ELISA to detect anti-phosphatidylcholine antibodies in patients with brucellosis $(\square)$ and healthy donors $(\mathbf{\square})$ : a, IgA isotype; b, IgG isotype.

specificity of the test. Specificity was determined by calculating the proportion of false positive responders among individuals expected to be non-responders (healthy controls). Sensitivity was determined by calculating the proportion of negative responders among those expected to be positive (brucellosis). An OD value of 0.55 was used as the cut-off point to determine positive reactors. Thus, the sensitivity and specificity for the ELISA-PC were: for IgG, 96.8\% and $96.5 \%$, respectively; and for $\operatorname{IgA}, 90.3 \%$ and $89.7 \%$, respectively (Table 4 ).

An independent relationship was observed between levels of IgG and IgA anti-PC by ELISA-PC and MAT or Coombs test. The correlation coefficients between the MAT and Coombs tests and the ELISA IgG and ELISA IgA tests are shown in Table 4. In this study, the sensitivity of the classical MAT was $90.3 \%$. All sera from the healthy control group were negative in the serological tests for brucellosis ( 0 of 29); however, three sera (out of 31) from the brucellosis group were negative in MAT (titre $\leqslant 20$ ). Significantly, all those MAT-negative sera were positive by ELISA-PC, of IgG and IgA isotypes. The observed proportion of agreement between MAT and IgG ELISA-PC was 0.94, with 29 of 31 results coincident. On the other hand, nine of 31 sera were Coombs-negative in the brucellosis group, but eight of the nine were ELISA-PC IgG positive, and seven were also IgA anti-PC positive.

Only one of 14 individuals clinically cured of brucellosis (group 4) had significant IgG anti-PC antibodies. In contrast, all the patients had positive values in the conventional $\mathrm{RB}$ test for brucellosis (Table 2).

Five of 35 sera from patients infected with other micro-organisms (Treponema pallidum, human immunodeficiency virus and hepatitis $\mathrm{B}$ virus) gave values of IgG anti-PC higher than those of the healthy group, three of them were VDRL positive ( $T$. pallidum and HIV infection). None of the patients infected with bacteria other than Brucella spp. had IgG anti-PC antibodies.

\section{Discussion}

Serum levels of antibodies of the IgG, IgM and IgA class against PC were measured by ELISA in patients with brucellosis and healthy human controls. The results show that, in contrast to healthy controls, a high proportion of brucellosis patients $(90-97 \%)$ produced $\operatorname{IgA}$ and $\operatorname{IgG}$ anti-PC antibodies during infection. To the best of our knowledge this is the first report describing the presence of such antiphospholipid antibodies in brucellosis.

Antibodies to phospholipids have been demonstrated as a result of a various clinical conditions such as infection with $T$. pallidum, Plasmodium falciparum and other micro-organisms, in diseases associated with inflammation of tissues, in immune disorders, during pregnancy and with aging [12]. Most of these antibodies are directed against cardiolipin, and to a lesser extent against other phospholipids, with few reports of anti-PC antibodies [13, 14].

The source of these anti-phospholipid antibodies is a matter of speculation. The most generally accepted

Table 4. Comparative evaluation and correlation between ELISA-PC, agglutination (MAT) and Coombs test

\begin{tabular}{|c|c|c|c|c|c|c|}
\hline \multirow[b]{2}{*}{ Method } & \multirow[b]{2}{*}{ Sensitivity (\%) } & \multirow{2}{*}{$\begin{array}{c}\text { Positive } \\
\text { predictive } \\
\text { value }(\%)\end{array}$} & \multirow[b]{2}{*}{ Specificity $(\%)$} & \multirow{2}{*}{$\begin{array}{l}\text { Negative } \\
\text { predictive } \\
\text { value (\%) }\end{array}$} & \multicolumn{2}{|c|}{ Correlation coefficient (r) } \\
\hline & & & & & MAT & Coombs test \\
\hline MAT & 90.32 & 100 & 100 & 90.63 & - & 0.534 \\
\hline ELISA-PC-IgG* & 96.77 & 96.77 & 96.55 & 96.55 & -1.847 & -0.2211 \\
\hline ELISA-PC-IgA* & 90.32 & 90.32 & 89.66 & 89.66 & -1.796 & -0.2372 \\
\hline
\end{tabular}

${ }^{*} \mathrm{OD}$ values $\geqslant 0.55$. 
hypothesis suggests an autoimmune reaction to host tissue components, so they are considered autoantibodies [15]. However, in the case of the anti-PC antibodies in brucellosis, although we do not have definitive evidence to exclude that hypothesis, some evidence supports the specific immune nature of these antibodies. First, the expression of PC on the outer membrane (OM) of Brucella spp., and strong interactions with proteins and lipopolysaccharides; second, the absence of an IgM response; and third, the sera of the brucellosis group were VDRL negative.

The external expression of phospholipids is not a general characteristic of these structural components. The OM in gram-negative bacteria is an asymmetric structure that provides a barrier to hydrophobic molecules. Nikaido and Nakae [16] suggested that the lipid portion of LPS is found only on the outer surface of the OM, whereas it is generally assumed that phospholipids are found only on the inner surface. However, the presence of dispersed phospholipid patches exposed on the outer leaflet of the OM of Brucella spp. has been suggested. [7]. Furthermore, whereas in Escherichia coli and other Enterobacteriaceae the $\mathrm{OM}$ is enriched in $\mathrm{PE}$ [5], the $\mathrm{OM}$ of $B$. melitensis is enriched in PC [6], an unusual phospholipid in bacterial membranes. Also, in the OM of Brucella spp. the interactions among the different structural components (proteins and lipopolysaccharide, including phospholipids) are stronger than in other gram-negative bacteria [17]. Although it is known that there is no established general principle that requires that lipids bind to foreign protein in order for the lipid to serve as antigen, this interaction could favour a special and specific immune response against PC. Moreover, additional evidence supporting a specific immune response of the host against $\mathrm{PC}$ is the fact that none of the sera from the brucellosis group was VDRL positive, in contrast to those from patients infected with $T$. pallidum or HIV.

The clinical utility of the detection of these anti-PC antibodies by ELISA obviously depends on its specificity and sensitivity. The results showed high levels of specificity and sensitivity for ELISA-PC, similar to some conventional serological tests for brucellosis. Thus, three patients who had negative sera in the MAT presented high levels of IgG and $\operatorname{IgA}$ anti-PC antibodies. However, one patient had a negative reaction in the IgG ELISA-PC but not in the MAT. Therefore, with respect to the healthy control group the detection of IgG anti-PC by ELISA gave meaningful predictive values for serodiagnosis.

On the other hand, IgG anti-PC was also found in five of 35 patients with other infections produced by $T$. pallidum, HIV and HBV. These results might be expected because of the serological cross-reaction among phospholipids and the strong anti-cardiolipin reaction produced after infection by those microorganisms [18-20].

In summary, the results of the present study demonstrate, firstly the presence of anti-PC antibodies during brucellosis, and secondly, that the detection of $\mathrm{IgG}$ anti-PC antibodies could be used to confirm a clinical diagnosis of brucellosis. Furthermore, the data obtained from cured patients (who were seropositive in the conventional test for brucellosis but negative in the ELISA-PC) support the initial hypothesis that the use of this PC-specific assay could also help in establishing a more precise serodiagnosis. Nevertheless, the determination of the distribution of titres of antibodies to $\mathrm{PC}$ in a larger group of patients over a long period, covering all phases of the disease, will enable us to establish the relationship between these antibodies and clinical outcome with greater accuracy.

This research was supported by the Departamento de Salud de Gobierno de Navarra (no. 95-1813). Fellowship support for M.A.C. from the Asociación de Amigos de la Universidad de Navarra is gratefully acknowledged.

\section{References}

1. Díaz R, Moriyón I. Laboratory techniques in the diagnosis of human brucellosis. In: Young EJ, Corbel MJ (eds) Brucellosis: clinical and laboratory aspects. Boca Raton, FL, CRC Press. 1989: $73-83$

2. Gamazo C, Vitas AI, López-Goñi I, Díaz R, Moriyón I Factors affecting detection of Brucella melitensis by BACTEC NR730, a nonradiometric system for hemocultures. $J$ Clin Microbiol 1993; 31: 3200-3203.

3. Pellicer T, Ariza J, Foz A, Pallarés R, Gudiol F. Specific antibodies detected during relapse of human brucellosis. J Infect Dis 1988; 157: 918-924.

4. Domingo S, Díaz R, Gamazo C. Antibiotic treatment induces an increase of the specific antibody levels in Brucella melitensis infected mice. FEMS Immunol Med Microbiol 1995; 12: 91-95.

5. Goldfine H. Bacterial membranes and lipid packing theory. $J$ Lipid Res 1984; 25: 1501-1507.

6. Gamazo C, Moriyón I. Release of outer membrane fragments by exponentially growing Brucella melitensis cells. Infect Immun 1987; 55: 609-615.

7. Martínez de Tejada G, Moriyón I. The outer membranes of Brucella spp. are not barriers to hydrophobic permeants. $J$ Bacteriol 1993; 175: 5273-5275.

8. Voller A, Bidwell D, Bartlett A. Enzyme-linked immunosorbent assay. In: Rose NR, Friedman H (eds) Manual of clinical immunology, 2nd edn. Washington, DC, American Society for Microbiology. 1980: 359-371.

9. Otero JR, Fuertes A, Palenque E, Noriega AR. Microtiteradapted method that facilitates the Coombs test for brucellosis. $J$ Clin Microbiol 1982; 16: 737-738.

10. Morgan WJB, MacKinnon DJ, Lawson JR, Cullen GA. The rose bengal plate agglutination test in the diagnosis of brucellosis. Vet Rec 1969; 85: 636-641.

11. Anonymous. Manual of tests for syphilis. NCDC Venereal Diseases Program. US Department of Health, Washington, DC, US Government printing office. 1969.

12. Wicher $\mathrm{K}$, Wicher V. Phospholipid antibodies in natural and experimental syphilis. In: Harris EN (ed) Phospholipid-binding antibodies. Boca Raton, FL, CRC Press. 1991: 98-105.

13. Jakobsen PH, Morris-Jones SD, Hviid L et al. Anti-phospholipid antibodies in patients with Plasmodium falciparum malaria. Immunology 1993; 79: 653-657.

14. Stern JJ, $\mathrm{Ng} \mathrm{RH}$, Triplett DA, McIntyre JA. Incidence of 
antiphospholipid antibodies in patients with monoclonal gammopathy of undetermined significance. Am J Clin Pathol 1994; 101: $471-474$.

15. Elkon KB. Autoantibodies: their nature and significance. In: Harris EN (ed) Phospholipid-binding antibodies. Boca Raton, FL, CRC Press. 1991: 59-72.

16. Nikaido $H$, Nakae $T$. The outer membrane of gram-negative bacteria. In: Rose AH, Morris JG (eds) Advances in microbial physiology, vol 20. London, Academic Press. 1979: 163-250.

17. Moriyón I, Berman DT. Isolation, purification, and partial characterization of Brucella abortus matrix protein. Infect Immun 1983; 39: 394-402.
18. Bacon PA, Davidson C, Smith B. Antibodies to candida and autoantibodies in sub-acute bacterial endocarditis. $Q \mathrm{~J} \mathrm{Med}$ 1974; 43: $537-550$.

19. Tardieu M, Powers ML, Hafler DA, Hauser SL, Weiner HL. Autoimmunity following viral infection: demonstration of monoclonal antibodies against normal tissue following infection of mice with reovirus and demonstration of shared antigenicity between virus and lymphocytes. Eur $J$ Immunol 1984; 14: $561-565$.

20. Vaarala O, Palosuo T, Kleemola M, Aho K. Anticardiolipin response in acute infections. Clin Immunol Immunopathol 1986; 41: 8-15. 